\title{
The Role of the Rational Soul in Hearing in Plato's the Timaeus
}

\author{
Kai Chen ${ }^{1, *}$ \\ ${ }^{1}$ Xinya College, Tsinghua University, Beijing, China \\ *k-chen18@mails.tsinghua.edu.cn
}

\begin{abstract}
The Timaeus is Plato's dialogue on the creation of the cosmos. It points out that Human beings' hearing perception is an important point to bridge the human body and soul. Usually, it is deemed teleologically designed by the Demiurge for their apprehension of the well-ordered cosmos, and, therefore, they can imitate it and then lead their own body and soul into a harmonious state. Centered around this topic, Andrew Barker and Elizabeth Lucia Lyon have respectively proposed two modalities to expound hearing. However, each hearing modality either fails to explain some contents in Timaeus or is inconsistent with the common experience in daily lives. The key problem is that they do not appropriately deal with the role of the rational soul in hearing. In view of it, this essay, based upon the similar working pattern between the world soul and the rational part of the human soul, makes some steps forward within the following aspects: the detailed way of the rational soul's intellectual cognition; the sorts of objects it recognizes; and its cooperation with the mortal parts of soul as well as somatic organs.
\end{abstract}

Keywords: the Timaeus, hearing, rational soul, intellectual cognition

\section{INTRODUCTION}

The Timaeus is a dialogue written in Plato's later period of life. It is a dialogue systematically discussing the creation of the world and its impressive mathematical order and beauty. Plato expressed his idea of "the cooperation of intellect and necessity in the psychophysical formation of man and other living things" in the latter-half of Timaeus [1]. He noted that, without human beings, the world would not be complete. The rational soul of human beings can reach a state of harmony if working properly with the spirited and appetitive souls; which, in the physical account of the Timaeus, means to revolute just as the World Soul. Under the circumstances, the auditory as well as visual sense, are teleologically designed by the Demiurge for human beings' apprehension of the well-ordered cosmos.

However, according to the current research of Timaeus, hearing, compared with sight, is conspicuously attached less importance by some scholars, such as T.K.Johansen and Cornford. Take Johansen for example, in his article "Perception and Cosmology", he mainly focuses on sight and merely deems the account of hearing similar to it in that they are both designed for human beings to imitate the cosmos and regulate the rational soul
[2]. There is no denying that the account of the two senses resembles each other in many aspects, but there are still some important characteristics, which is tightly connected with the rational soul, exclusively possessed by hearing. More exactly, it is the three significant aspects that deserve more investigation: the detailed way of the rational souls' cognition or interpretation in hearing; the specific compartmentalization of the objects that the rational soul recognizes in hearing; as well as the interaction between the rational part and the mortal part (both the spirited and the appetitive) and the physical mechanism that cooperates with it. This essay would provide an amended hearing modality based upon that of Barker and Lyon and make some steps forward within the aforementioned aspects.

\section{LITERATURE REVIEW}

In the Timaeus, the most direct description of hearing is in $67 \mathrm{~b}$ :

In general, let us take it that sound is the percussion of air by way of the ears upon the brain and the blood and transmitted to the soul, and that hearing is the motion caused by the percussion that begins in the head and ends in the place where the liver is situated [1]. 
According to the definition above, Andrew Barker offers his version of the hearing modality which involves two motions. Motion 1 refers to sound which is caused by "the percussion of air by way of the ears upon the brain and the blood and transmitted to the soul" while Motion 2 constitutes the sense of hearing which is started by the percussion of the soul in the head and not finished until

percussion of air
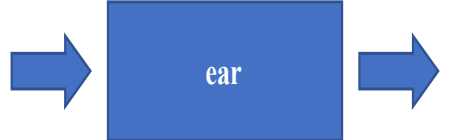

brain/head/

the rational soul

the liver is affected. Eventually, such percussion would generate a series of tupos in the liver, which is then reflected to the mortal soul (the appetitive part) with the form of phantasma. Apart from it, Barker adds that the rational soul in the brain would require the feedback of the mortal soul for further interpretation [3].

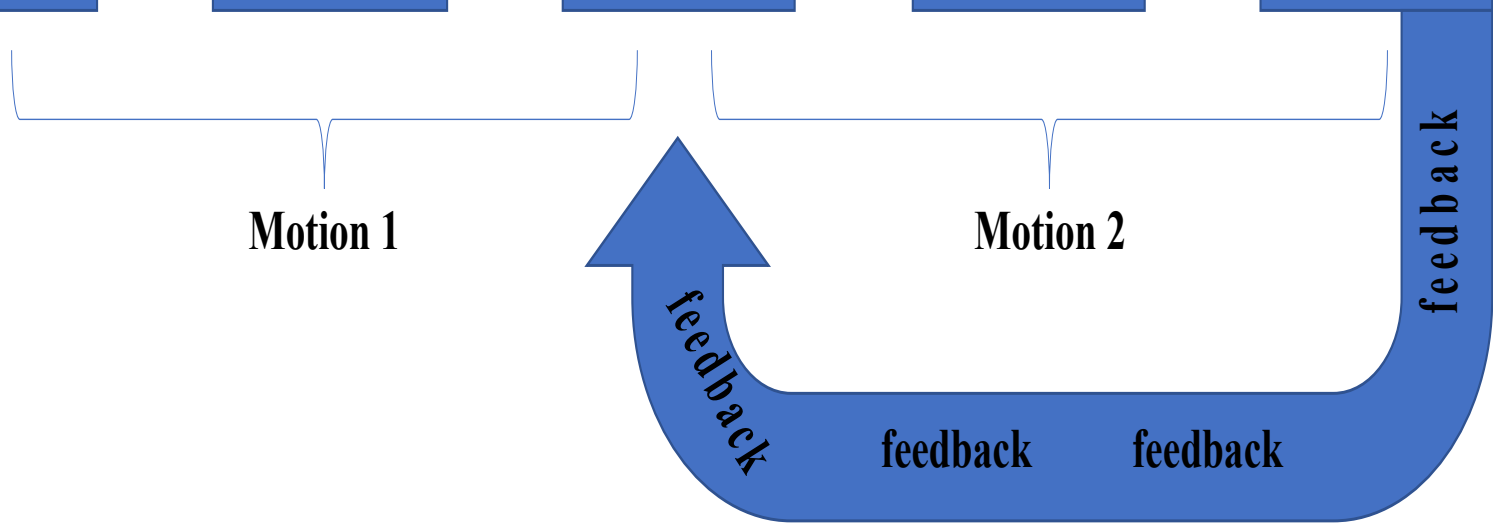

Figure 1: Barker's hearing modality

By contrast, Elizabeth Lucia Lyon proposes another different modality which entails only one motion. She takes the bipartite structure of the definition to distinguish the object of hearing from the sensation of hearing. "while the percussion of air upon the brain and blood specifies the object of hearing, the motion of the percussion from the head to the liver specifies the sense organ" [4]. The percussion transmitted to the liver is not caused by the rational soul but from the outside air, and the head is merely a passing point of the transmission during which the rational soul is not participated.
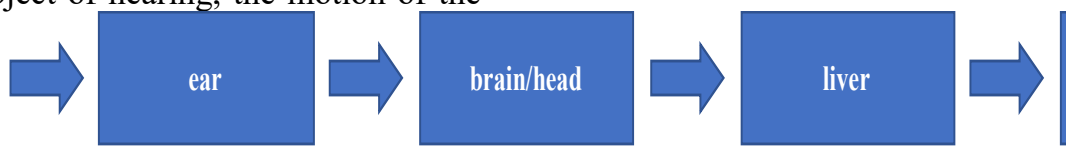

the mortal soul

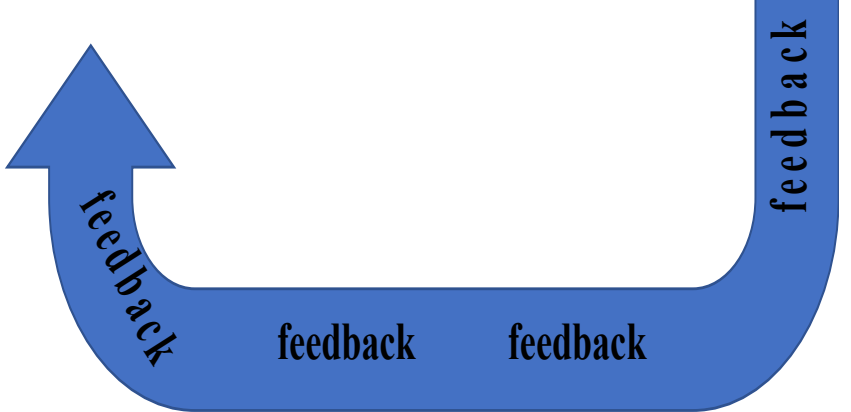

Figure 2: Lyon's hearing modality

The cause of the conspicuous distinction of the number of motions in Barker's and Lyon's modality lies in that they have divergent views over whether the rational soul actually participates as soon as the percussion of air is transmitted to the head or brain. Both explanations have its own disadvantages.

On the one hand, if the rational soul actually participates, it would cause the following problems. 
Firstly, the malfunction of the rational soul would affect the proper working of the hearing perception afterwards. Nevertheless, it does not make sense - as is argued by Elizabeth Lycia Lyon, "the disorder of the rational soul on the one hand prevents cognition, but does not impair the transmission of perception. . . in short, not to see or hear anything right is to see or hear everything wrong, not to see and hear nothing." [4]. Secondly, the rational soul, in Barker's modality, would participate twice in all-the first time is its being directly affected by the external air while the second time is its further interpretating the feedback of the mortal soul. However, Barker fails to provide an integrated account of how the rational soul deal with the mutual relationship between its two participations, in other words, what kind of factors necessitate the rational soul participating twice instead of only once [3].

On the other hand, if the rational soul does not actually participate until it receives the feedback from the mortal soul, a new problem would arise. In her modality, the rational soul identifies things just on the basis of feedback from the mortal soul which lacks the ability of intellectual cognition. Under the circumstances, there will be no denying that the body and perception completely act as a kind of inhibition of the soul in the pursuit of truth, as is claimed in the Phaedo [5]. However, in the Timaeus, the body and perception, to some extent, are in fact endowed with a teleologically positive function. As is indicated in $47 \mathrm{c}-\mathrm{d}$, Timaeus calls the sight and hearing "the god's gifts" for us to understand the inner harmonious order of the cosmos [1]. It conspicuously fails to fit in with that our human intellect, through hearing, has no access to what the outside object is.

Additionally, there is a common problem for both modalities proposed by Barker and Elizabeth. It is noteworthy that they both agree that the rational soul will further interpret the feedback from the mortal soul. However, how will the rational soul get in touch with the mortal soul since they are placed in different parts of the body? And in which way the rational soul will complete its intellectual interpretation?

For convenience, the problems above would be separately concluded as follows.

[Problem A] the conflict with the fact that the disorder of the rational soul does not impair the transmission of perception.

[Problem B] the failure to deal with the twice participation of the rational soul

[Problem C] the failure of the rational soul to grasp what the object is

[Problem D] the detailed way of the rational soul's interpretation and its communication with the mortal part
Essentially, all the problems above arise from the lack of plausible understanding of the specific way of the rational soul's intellectual cognition under the circumstance of the hearing-perception. The current study will discuss these problems from the perspective of the rational soul's own characteristics (problem B, C and D) and how its individual functions harmoniously interact with the other parts of the human soul as well as the bodily organs involved in hearing (problem A and D).

\section{THE GENERAL WORKING PATTERN OF THE RATIONAL PART OF THE HUMAN SOUL-THE ISOMORPHISM OF THE WORLD SOUL AND THE HUMAN SOUL}

An important theory in the Timaeus is the isomorphism of the world soul and the human soul (the rational soul), as is pointed out in 41d-e.

When he (the demiurge) had finished this speech, he turned again to the mixing bowl he had used before, the one in which he had blended and mixed the soul of the universe. He began to pour into it what remained of the previous ingredients and to mix them in somewhat the same way, though these were no longer invariably and constantly pure, but of a second and third grade of purity. And when he had composed it all, he divided the mixture into a number of souls equal to the number of the stars and assigned each soul to a star. He mounted each soul in a carriage, as it were, and showed it the nature of the universe [1].

As is inferred above, the rational part of the human soul shares the same materials and structure with the world soul. Therefore, an investigation of the working mechanism of the world soul might shed light on the understanding of the intelligence of the human soul. In the Timaeus, the cognition of the world soul, deemed the "ideal intellectual cognition" by Klaus Corcilius [6], are described as follows:

Because the soul is a mixture of the Same, the Different, and Being (the three components we've described), because it was divided up and bound together in various proportions, and because it circles round upon itself, then, whenever it comes into contact with something whose being is scatterable or else with whose being is indivisible, it is stirred throughout its whole self. It then declares what exactly that thing is the same, or what it is different from, and in what respect and in what manner, as well as when, it turns out that they are the same or different and are characterized as such [6].

Corcilius interprets it into three main points.

1) Structure: the world soul consists of being (the divisible being and indivisible being), sameness (the divisible sameness and indivisible sameness) and 
difference (the divisible difference and indivisible difference), and the final mixture of them is divided by the Demiurge into "the harmoniously proportionate parts" [6].

2) Active Access: the statement "(while self-rotating) whenever it comes into contact with something" does not denote "reciprocal contiguity between perceptible bodies" since the world soul is an intelligible item. Instead, "come into contact" ( $\varepsilon \varphi \alpha \dot{\pi} \tau \omega)$ here is "just a word for access" [6].

3) Great Comparison: "each item is compared with every other item in the same domain and with every other item of the other item in the following respects: what they are, where they are, the manner in which they are, and when they are." [6].

In view of the same constitutes with the world soul, the detailed reasoning method of the human soul should be the similar pattern. Corcilius actually insinuates it when he tries to argue against the "two-step view". In the Timaeus, the circle of the Different "proclaims"

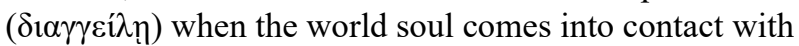
something perceptible while the circle of the Same "reveals" ( $\mu \eta v v ́ \sigma \eta)$ when it is concerned with something intelligible. Here, as is contended by Corcilius,

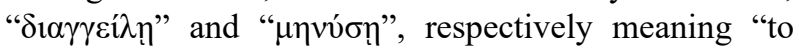
give notice by a messenger" and "to make known" in ancient Greek, does not "force a reading on us that endows each of the two circles with a separate cognition of its own"[6]. Instead, they merely indicate that "the different parts of the world soul faithfully convey whatever information they convey" without being aware of the information they themselves convey". In other words, he suggests that the use of these words by Plato is best taken as "the absence of inhibiting conditions for the exercise of the world soul's cognizing" [6]. To vindicate it, he further compares the cognition of the world soul with that of young humans:

Whenever they encounter something outside them characterizable as same or different, they will speak of it as "the same as" something, or as "different from" something else when the truth is just the opposite, so proving themselves to be misled and unintelligent. Also, at this stage souls do not have a ruling orbit taking the lead. And so when certain sensations come in from outside and attack them, they sweep the soul's entire vessel along with them. It is then that these revolutions, however much in control they seem to be, are actually under their control [6].

As we can see, the cognition of young humans is described by the similar relational words to that used in the world soul. It exactly fits in with the aforementioned quotation on the isomorphism of the world soul and the human soul (the rational soul). The only difference is that its proper motions (a ruling orbit taking the lead) are disturbed. Since the "messenger" malfunctions, it fails to "proclaim" or "reveal" the information accurately. In Corcilius" article, "the removal of the cause for falsehood in human judgement" is intended to be taken as the

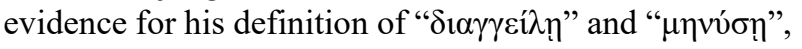
namely "the absence of disturbing influences" of the world cognition, and further for his argumentation against the "two-step view" [6]. In return, we can also deem it the evidence for the similar cognitive pattern of the rational part of the human soul to that of the world soul- their difference lies in whether there are external disturbing influences imposed on it instead of some original internal structural factors.

In a nutshell, this paper intends to vindicate that the relation between the world soul and the embodied rational soul can be compared to that between a wellfunctioning computer and a temporarily malfunctioning one. That is to say, the rational part of the human soul, ideally, would also actively cognize perceptible or intelligible things by means of comparison instead of immediate cognition when self-rotating. As long as the bugs arising from embodiment can be restored, its cognitive pattern would be almost the same with that of the world soul.

After introducing the general working pattern of the rational soul, this paper continues to investigate how it participates particularly in the process of hearing.

\section{THE PARTICIPATION OF THE EMBODIED RATIONAL SOUL IN HEARING}

\subsection{The distinction between the head and brain}

Let us return to the original definition of sound and hearing in the Timaeus again:

Sound is the percussion of air by way of the ears

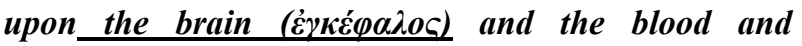
transmitted to the soul, and that hearing is the motion caused by the percussion that begins in the head

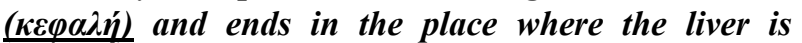
situated [1].

Undoubtedly, as is proposed by Barker, it is reasonable to consider that the hearing perception involves two motions since the definition above clearly mentions two sequential stages - one route, generally, is from the external air to the brain or head while the other, following the first one, is from the brain or head to the liver. Although Barker understands the broad picture in a right way, he misunderstands one significant detail- he contends that the two motions are tightly related, that is to say, motion 1 obviously has an influence on motion 2 , from which problem A arises. The reason for such misunderstanding is that he confuses "the brain" with "the head"- the former is close to the termination of motion 1 while the latter is the starting point of motion 2 . If they are deemed the same, naturally, the two motions 
would be deemed related with each other since they are almost end-to-end. Nevertheless, it is not a plausible

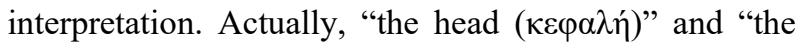

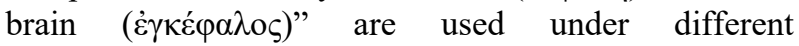
circumstances in the Timaeus and, therefore, have different connotations.

In terms of the head, it is first pointed out along with the description of the creation of the human body:

Copying the revolving shape of the universe, the gods bound the two divine orbits into a ball-shaped body, the part that we now call our head. This is the most divine part of us, and master of all our other parts [1].

The aforementioned paragraph should be connected with the theory of tripartition of the human soul in the Timaeus: the immortal soul (the rational soul), the spirited soul and the appetitive soul are separately placed in different sections of the human body, namely the head, the chest and the part beneath the midriff. In this sense, the head is made ball-shaped because this shape resembles "the revolving shape of the universe" and, therefore, enables the head to function as "an appropriately spherical seat of the circular motions" of the rational part of the human soul [1].

However, in terms of "the brain", it is described as follows:

And in making his initial distribution, he (the Demiurge) proceeded immediately to divide the marrow into the number and kinds of shapes that matched the number and kinds of shapes that the types of soul were to possess, type by type. He then proceeded to mold the "field", as it were, that was to receive the divine seed, making it round, and call this portion of the marrow "brain". Each living thing was at its completion to have a head to function as a container for this marrow [1].

There is no denying that both "head" and "brain" are the container for the rational soul. However, they slightly differ from each other in two aspects. Firstly, "head" emphasizes a physical part of human body while "brain" focuses on the bond connecting body soul. Secondly, in a spacial sense, "brain" is contained in "head" as is revealed by the words "each living thing was at its completion to have a head to function as a container for this marrow".

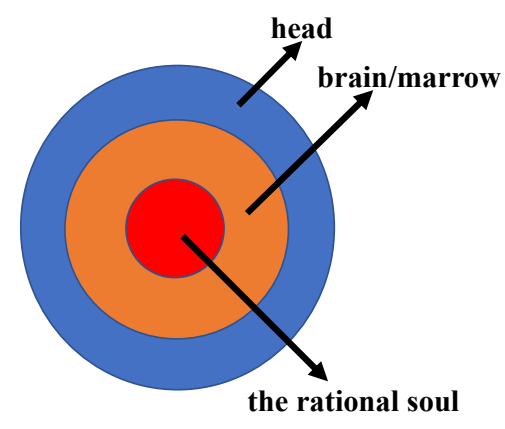

Figure 3: The relation between the head and brain

(It is necessary to clarify that Figure 3 just reflects the abstract relation, in terms of containing and being contained, between the head and the brain. The three concentric circles are merely the diagrammatic sketch in an abstract sense - the different colors are just used, for convenience, to distinguish different parts, and they are not meant to indicate the real color; also, although the shape of circle, indeed, fits in with the shape of head and brain, the smallest red circle referring to the rational soul does not mean that the rational soul is simply shaped like circle - actually it is hard to determine its external shape since it is not a material object. Additionally, someone might ask how the immaterial and non-perceptible rational soul can, in a spatial sense, contained by the brain and head which both belong to the perceptible domain. Since this question is not tightly related to the topic of hearing, it would not be paid attention to in this essay. If you are interested, please turn to Johansen's article "Body, Soul and Tripartition" in which he argues that it is the perceptibility of body that distinguishes it from the soul" [7], and whether it occupies the space or not cannot be deemed the valid standard to distinguish the body from the soul - that is to say, "the soul stuff would thus not add to the volume of body, even whilst it was extended along the body. . . body is differentiated from soul by having specific spatial attributes,such as depth and solidity, rather than by the possession of spatial attributes as such". All the explanations above would also be applied to other figures in this essay.)

In view of it, motion 1 and motion 2 is not end-to-end. Before arriving at the head, the percussion generated by air undergoes the same route, namely by way of ears. However, it is at the head that the route is separated into two different directions: one route, namely route 1 , further reaches the brain and then the rational soul contained within it while the other, namely route 2 , continues extending to the liver. 


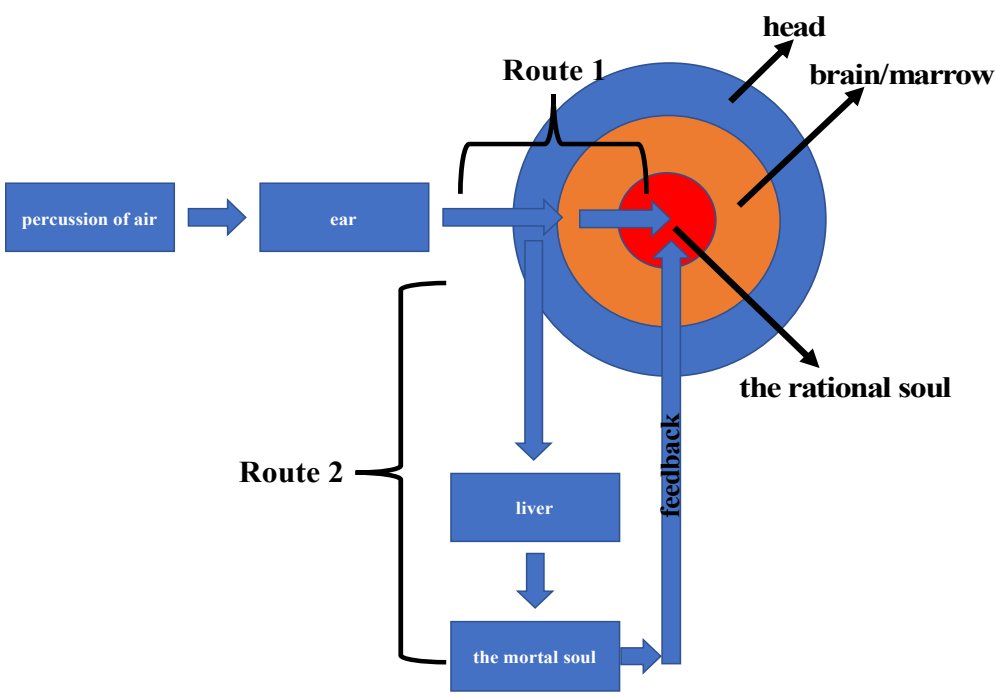

Figure 4: My version of hearing modality

Compared to Barker's modality, this version, mainly based upon the meticulous distinguishment between the head and brain, is more plausible in that the disorder of the rational soul would not impair the transmission of hearing perception to the liver since within route 2 the head merely functions as a passing point, just as what Lyon claims, and route 1 , in which the rational soul actually participates, is relatively independent from it.

Next, this essay argues in detail how the rational soul participates within this modality. Basically, as is indicated by Figure 4, this essay embraces Barker's view that the rational soul participates twice-the first is within route 1 while the second is that it receives and interprets the feedback from the mortal part. The difference is that the distinctive meanings of the twice participations and the mutual relations between them would be further clarified and this is exactly what is absent from Barker's article.

\subsection{The first participation of the rational soul}

In terms of the first participation within route 1 , it can be described as the active reach for sound particles of the rational soul. This statement is based upon the active recognition of the world soul mentioned in 3.1. Because of the complete surrounding of the cosmos, the world soul is accessible to everything actively. Although the rational soul has no direct access to the outside environment, its activeness of recognition has not changed. Therefore, once the sound particles from the outside enters its region, it is hard to imagine that the active rational soul should remain indifference or ignorant and wait until the mortal soul transmits the feedback to it. In this sense, technically, within route 1, it is not simply that sound particles are "transmitted" to the brain and the rational soul. Instead, what happens is that sound particles and the rational soul are heading towards each other.

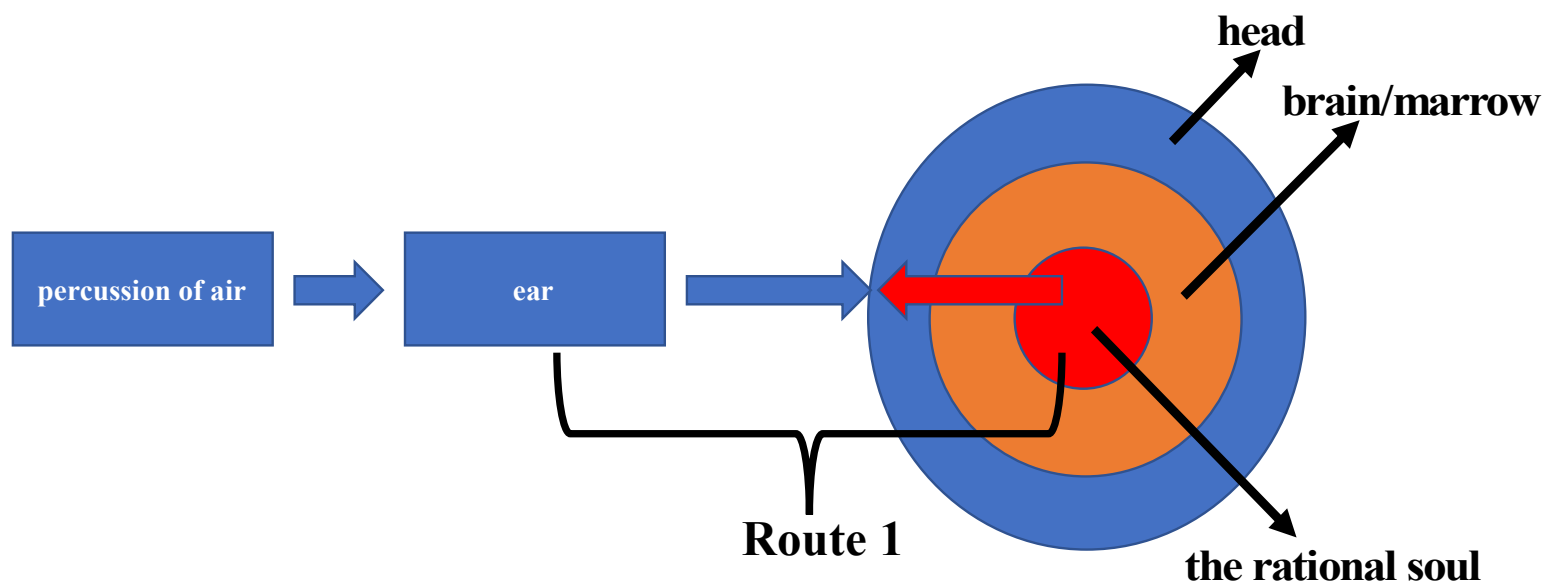

Figure 5: the rational soul's active reach

Furthermore, it is at the first participation that the rational soul begins to grasp the external object itself.
As is contended by Cornford, the external part and the internal part have different ways of transmission of sound 
[8]. In terms of the external transmission, it is commonly deemed as a recirculation of particles of air, also called "sound particles", from the outside to the inside. As is contended by Lyon, "there is no void in the Timaean universe, motion must be explained by a recirculation of matter", which means that "as material moves away from a given location, it is simultaneously replaced by other material that takes its place" [4]. And this type of matter, within the process of hearing, is precisely air since in the Timaeus "the explanation of consonance immediately follows a thorough explanation of the movement of air in breathing, and we have been told that air is hearing's

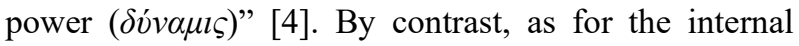
transmission, it is a succession of disturbances of bodyone disturbance of body is passed on in a chain reaction with some parts affecting others in the same way as they were affected, until it reaches the center of consciousness and reports the property.

The two different ways of transmission indicate that the external transmission is the sound itself (sound or air particles) while the internal one is just the influence of sound (the inner disturbances of body caused by sound). Evidence for it can be found in the original definition of sound and hearing brought up at the beginning of 3.2only the one transmitted from the outside part to the brain and the soul by way of the ears is called sound or "the percussion of air" while the transmission on the other route to the liver can be only called "the motion caused by the percussion" which means during this state it is no longer the sound itself but the affection caused by the sound.

Therefore, when the rational soul actively reaches the sound particles as soon as they enter the brain, it approaches what the hearing object $i s$. However, this only vindicates that the rational soul has access to the essence of the hearing object. We have not yet discussed what enables the rational soul to eventually recognize and interpret it. This essay thinks that it should be attributed to the congruence between the inner structure of the rational soul and the composition of the hearing object.

As is articulated in 3.1, since "the structure of the world soul consists in the arrangement of the harmoniously proportionate parts into which the Demiurge divided the final mixture of the elements", the human soul, the less-pure version of the world soul, should possess "harmoniously proportionate parts" as well. In the Timaeus, such harmonious proportion is mathematically presented through the figure of the tetractys:

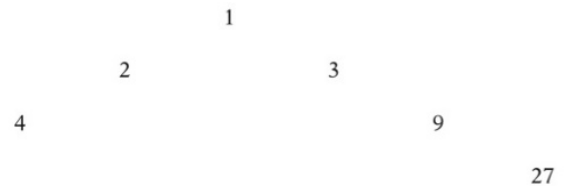

Figure 6: tetractys, from Jessica Wiskus [9]
As is pointed out by Timaeus, "whenever of three numbers (or bulks or powers) the middle term between any two of them is such that what the first term is to it, it is to the last, and, conversely, what the last term is to the middle, it is to the first, then since the middle terms turns out to be both first and last, and the last and the first likewise both turn out to be middle terms, they will all of necessity turn out to have the same relationship to each other, and, given this, will all be unifie.”. Jessica Wiskus, in her article called "On Song, Logos, and the Movement of the Soul: After Plato and Aristotle", interprets the aforementioned sequences as that "all the terms are interchangeable. . . there is a potential for $1: 2$ to be as 2:4-for 1 to be interchangeable with 2 and 2 interchangeable with 4 , i.e. for what a number is to become what it is not" [9]. Additionally, she further introduces the Greek notion $\delta v v \alpha \mu \varsigma$ - it, in a technical way, is used to "describe the power or potential that each number has in relation to itself", and potential, essentially, is about "something yet to come or something having passed" and "involving a condition of non-presence"-it is exactly this potential or $\delta v$ vouls that effectuate the tetractys [9].

To conclude, this kind of inner structure implies two aspects of the cognitive ability of the rational part of the human soul - one is its inner harmonious proportionate parts(Aspect 1), and the other is that such proportion, with the connotation of potential or divvals, insinuates the ability to transcend what is given at present(Aspect 2), as is pointed out in the Phaedo [5]. Interestingly, the composition of the hearing object is exactly in congruence with the two aspects so that it can be intellectually recognized and interpreted by the rational soul - this is what has already been mentioned in 3.1 that "on the basis of the "like is known by like' principle" the world soul as well as the human soul recognizes things "when there are the same, similar, or deviant arrangements in the things it encounters" [6].

In the Timaeus 47b-d, the hearing objects are compartmentalized into three sorts, namely harmony, speech and rhythm. However, only harmony is comprehensively expounded later. It is presented as a form of pitches in 80a-b: "Sounds that appear to us as high pitched or low. On the one hand, sometimes they are inharmonious on account of the dissimilarity of the motion caused by them in us as they move towards us. On the other hand, sometimes they are harmonious on account of their proportionality. For the slower sounds catch up to the motions of the earlier and swifter ones which have already desisted and arrived at congruency. To these motions those sounds, by adding their motions, move the former ones. But in catching up, the slower sounds do not disturb them by throwing in a different motion. Rather, by attaching the beginning of a slower motion in accordance with the likeness of the swifter motion, now slowing down, they blend one single sensation from high and low." [1]. In this sense, harmony 
is tightly related to Aspect 1 (harmony is not connected to Aspect 2 since it is only about what is given at present) and this is why it is within the rational soul's range of cognitive objects.

In terms of speech and rhythm, although they are not attached much importance to in the Timaeus, Wiskus expounds that their composition perfectly fits in with Aspect 2. As for speech, it should be understood as "double meanings", namely ratio and word: ratio refers to "(in Ancient Greek) a mathematical relationship between a long and short syllable (such as 2:1)", and, take $\lambda$ ó $\gamma$ os as example, "the first syllable fulfills its potential as first not through its sustained sounding. . . as if it were to be brought surreptitiously into the presence of the second" (this is what harmony would be like-the later sounds catch up with the earlier sounds), instead, it achieves its potential "thanks to its absence"-_an absence that makes possible its being bound together with the second"; similarly, word means "a gathering together of sensation through time", and present and potential syllables thus unite as meaning, in other words, it is to "gather together its sense through a two-fold dimension of pronouncement and absence, actuality and potentiality". The same is also true with rhythm. In the Ancient Greek, rhythm "carries the sense of motion or time constitute through a proportion or symmetry of parts", and such motion or time "is perceived as a continuum between potentiality and actuality-between the already-absent past and the yet-to-come future". In summary, both speech and rhythm partake of potential or

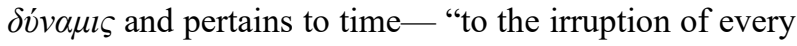
'now' through the not-now" [9]. Since the rational soul is enabled by its inner structure (tetractys) to transcend what is given at present, it makes sense that it can intellectually recognize speech and rhythm in hearing.

To conclude, the first participation of the rational soul in hearing is like this: as soon as sound particles enter the brain, the rational soul actively reaches for it, and at this time what reach the brain is the sound itself (what the sound is) instead of the affection caused by it, on account of which the rational soul gains the access to the essence of its hearing objects. Furthermore, the rational soul can also intellectually recognize and interpret the information carried by sound particles since there is a perfect congruence between its inner structure and the composition of its hearing objects. This explanation resolves the problem arising from Lyon's modality that the rational soul fails to grasp what the hearing object is.

\subsection{The second participation of the rational soul}

The active reception of the rational soul (first participation) is only one part of the complete pattern of cognition. If the rational soul only participated once, the working of intellectual cognition in hearing would have nothing to do with the somatic organs underneath the head and the mortal parts of the human soul. In this sense, embodiment would just be meaningless for the rational soul on account of its no contribution to the pursuit of truth.

Suppose this statement appeared in the Phaedo, it might be deemed an appropriate one since Socrates, the frequent character in Plato's works, had explicitly expressed his despise for the body. He puts it that "the philosopher's soul utterly despises his body and flees from it, seeking to be alone by itself" [5]. However, in the Timaeus, the body, as well as the tripartition, is not a sort of prison for the rational soul. In contrast, as is explained by Johansen, we human beings are created by the lesser gods "as a teleological system in which motions that arise by simple necessity and rational motions are combined", and "the rational order of the soul, post embodiment, is not one in which only the motions of the intellect thrive but a complex order in which other psychic motions operate alongside those of the intellect in common pursuit of the human good" [7]. In view of it, we are supposed to investigate how the rational soul, particularly in hearing, interacts with the mortal parts of soul, how the somatic mechanism supports such interaction and, further, how all of them are regulated and led into a harmonious state of cooperation - this is what we fail to see in the first participation of the rational soul since, during the first participation, the rational soul completes its intellectual cognition mostly by itself.

Before the detailed analysis of the rational soul's second participation, a brief introduction of what happens between the two participations is necessary since, for one thing, as is indicated by my version of hearing modality, the second participation does not happen immediately after the first one; for another, some points within the explanation of the intermediary process between the first and the second participation would function as a preparatory step for our further understanding of the cooperation between the three parts of the human soul which would be described afterwards.

As is mentioned above, the route of transmission is separated into two different and independent directions at the head-route 1 further reaches the brain while route 2 continues extending to the liver; furthermore, route 1 is the transmission of the sound particles, namely the sound itself, alongside with the active reach the rational soul while route 2 is merely a succession of the disturbances of body caused by the sound.

When the disturbances are transmitted to the liver, as is contended by Barker, they "impinge on the liver as tupoi ( $\tau \dot{v} \pi o l$ )" which means "the impression made by one thing on another through pressure or impact", and the tupoi are reflected from the liver to the appetitive soul as "eidola $(\varepsilon i \delta \omega \lambda \alpha)$ " or "phantasma ( $\varphi \alpha \dot{v} \tau \alpha \sigma \mu \alpha)$ " which carries "a powerful emotive charge" and "are conceived representationally as 'pictures"”. [3]. 


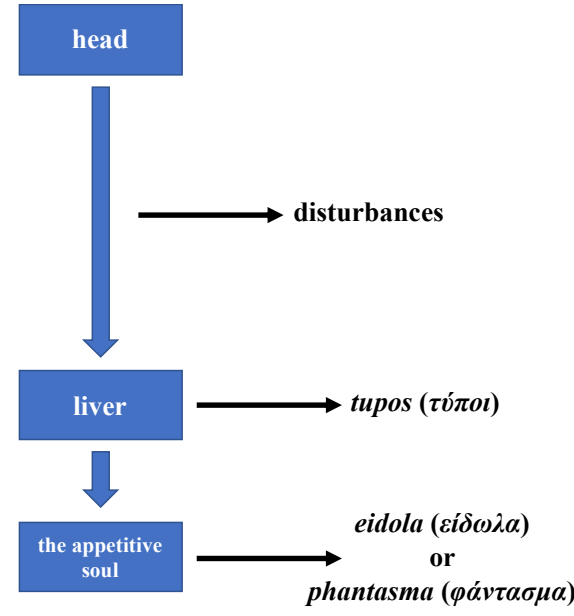

Figure 7: from the head to the appetitive soul

The procedure above implies one important function of the liver in hearing - it is "adjacent to" or "connected with" the appetitive soul, and it is from the eidola $(\operatorname{ci} \delta \omega \lambda \alpha)$ reflected from the liver that the appetitive soul experiences pleasure or pain. In the Timaeus, the liver, made dense, smooth and bright, is deemed to be able to receive the disturbances' impinging and then to reflect it like a mirror through its smooth surface. Because of this special characteristic, it is reasonable to deduce that the disturbances transmitted from the head wound impinge tupoi ( $\tau \dot{\pi} \pi o l)$ on the liver according to the real pitches of the sound - the mathematically harmonious combination of pitches would contribute to the restoration of the liver to its normal state (pleasure) while the disproportioned pitches would cause an unnatural disturbance against its normal state (pain), and such messages of pleasure and pain would further be reflected, with a form of eidola ( $\varepsilon i \delta \omega \lambda \alpha)$ or phantasma ( $\varphi \dot{\alpha} v \tau \alpha \sigma \mu \alpha)$, to the appetitive soul situated near the liver, on account of which Barker thinks that "the appetitive soul act as a receptor for anything that is reflected from the liver's smooth surface" [3].

Nevertheless, tupoi ( $\tau \dot{\pi} \pi o l$ ) merely retain "the physical form of harmonious movement"-they are impossible to directly present the mathematical framework and the potential or $\delta \dot{v} v \alpha \mu \iota$ implied within it; also, the appetitive soul, one of the two mortal parts of the human soul, lacks the capacity of intellectual analysis - it can only passively feel the pleasure or pain caused different types of impinging on the liver. To conclude, the liver fails to reflect all the information carried by the sound, and the appetitive soul is unable to interpret the information as well. This gap determines that sometimes the pleasure or pain of the mortal soul might not fit in with the cognition of the rational part. As we have seen, the hearing objects can be compartmentalized into three sorts: harmony, speech and rhythm. It is highly possible that one sort would appear simultaneously with another one-for example, once a rhapsode, playing the lyre, sings a poem to the public, his listeners would receive all the three kinds of hearing objects at the same time. In view of it, even there are some malicious lyrics or wrong rhythms within his song, as long as the melody and the accompanying music stays harmonious, the appetitive soul would still get a feeling of pleasure since what the liver receives is merely the disturbances resulting from the music instead of the sound itself, and it is impossible for it to interpret the inner information carried by the sound. In order to deal with this problem, it is necessary for the rational soul to participate for the second time - to regulate the appetitive part.

Now let's return to the point where the appetitive soul receives the eidola $(\varepsilon i \delta \omega \lambda \alpha)$ or phantasma ( $\varphi \alpha \dot{v} \tau \alpha \sigma \mu \alpha)$ from the liver. Afterwards, as is both mentioned in Barker and Lyon's hearing modality, the appetitive soul would send its feedback to the rational soul. It is at this time that the rational soul begins its second participation. Whereas, during this stage, it would not do analysis to the inner structure since this project have already been completed in the first participation. Instead, the task for it is to make a comparison between the former analysis and the current feedback.

Take the rhapsode sing the poem for example again, in that case, the appetitive soul would gain a sense of pleasure and thus report the messages of pleasure to the rational soul without the awareness of the improper language information as well as the disproportioned rhythm. However, before the feedback, the rational soul has intellectually analyzed all the information of the sound, including the harmony, speech and rhythm it carries. Therefore, it has the capacity to recognize the incongruence between what it interprets beforehand and what the appetitive soul reports, and then it would conclude that this kind of pleasure felt by the appetitive part is not appropriate.

However, since the rational soul and the appetitive soul are situated in different parts of the human body, how can the appetitive soul send its feedback to the rational part, and how can the rational soul, in return, give its order to the appetitive one and finally make it obedient? This essay thinks that such communication is realized by a particular physical mechanism which involves the blood, heart and liver.

In the Timaeus, such mechanism is described as follows:

The heart, then, which ties the veins together, the spring from which blood courses with vigorous pulse throughout all the bodily members, they set in the guardhouse. That way, if spirit's might should boil over at a report from reason that some wrongful act involving these members is taking place--something being done to them from outside or even something originating from the appetites within--every bodily part that is sensitive may be keenly sensitized, through all the narrow vessels, to the exhortations or threats and so 


\section{listen and follow completely. In this way the best part among them can be left in charge. [1]}

As is inferred above, blood, pumped from the heart, acts as an important vehicle travelling among all the three parts of the human soul as well as different somatic organs. Luc Brisson concludes that in the Timaeus blood's capacity to be the agent of transmission can be attributed to a few factors: to begin with, blood, "nothing else than the food and drink cut up and melted by the hot or fiery substance within us, plus particles of this fiery substance whose presence accounts for its red hue", is made out of all the four elements, therefore "it is able, according to the principle that the same is known by the same, to transmit information coming from any variety of sensible things made out of the same four elements"; also, on account of a lot of fire, the most mobile element, in it, blood "has great mobility and consequently it is a very good agent of transmission; finally, the moving range of blood is everywhere in the body, "so that it is always ready to carry information sent by any part of the body to the rational part of the soul" [10].

And particularly under the circumstances of hearing, blood exhibits its functions like this:
Firstly, once the immortal soul receives eidola $(\varepsilon i \delta \omega \lambda \alpha)$ or phantasma ( $\varphi \alpha \dot{v} \tau \alpha \sigma \mu \alpha)$ reflected from the liver, it would send its feedback to the rational soul by the help of blood. Then, after the rational soul gets the feedback and further detects something wrong with it, the spirited soul, the other part of the mortal souls which is situated between the rational one and the appetitive one, would be stimulated, and since it is near the heart, it would with vigorous pulse force the heart, said to tie the bodily veins, to spurt out the certain blood, which carries the command from the reason, to the liver. Afterwards, when the blood flow reaches, the liver would be threatened by physical affections, as is said in the Timaeus that "it would curve and shrivel up the liver's lobe and block up and close off its receptacles and portal fissures, thereby causing pains and bouts of nausea" [1] - Karfik puts it that "there is power emanating from the intellect that produces imprints in the passive matter of the liver. . . these imprints, however, are thoroughly corporeal qualities, such as bitterness and sweetness" [11]. Finally, the pain of the liver would again be reflected to the appetitive soul through the form of eidola $(\varepsilon i \delta \omega \lambda \alpha)$ or phantasma ( $\varphi \alpha \dot{v} \tau \alpha \sigma \mu \alpha)$, and this process would not stop until the appetitive part sends the correct feedback in congruence with the former analysis of the rational soul.

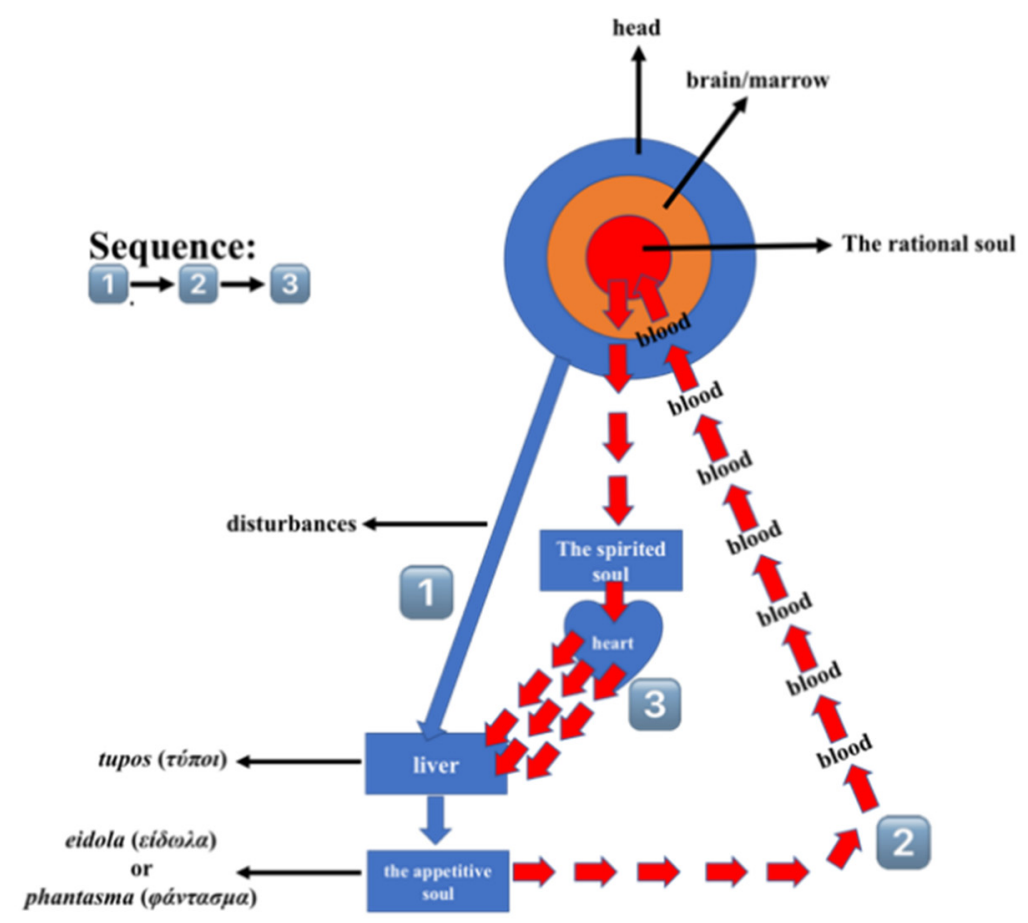

Figure 8: The communication supported by blood

To conclude, after receiving the feedback, the rational soul does not regulate the appetitive part by directly acting upon it. Instead, it requires the spirited soul, functioning as an intermediator, to send its orders, during which blood acts as an important vehicle. Also, it is noteworthy that the liver and heart are two significant somatic organs that are tightly connected to the two mortal parts of the human soul in hearing. As for the appetitive part, it is from the liver that it feels the physical hearing perceptions and is physically threatened by the rational soul to correct its feedback; in terms of the spirited soul, it is by the help of the heart, the blood pump, that it can transmit the order from the brain to the liver. 
Without their cooperation, the rational soul is impossible to complete its second participation.

In view of it, we should rethink about Lyon's definition of pleasure and delight in her article "Ethical Aspects of Listening in Plato's Timaeus". She states that pleasure or pain of consonance, happening in the mortal soul (the appetitive part), is the outcome of the restoration or destruction of the sense organ imparted by the object of hearing [4]. Furthermore, the fool and the intelligent actually share this kind of pleasure and pain, but the difference is that the intelligent would make use of the rational soul's active powers, namely the capacities in figuring out the inner order of the sound and in recognizing the sensory objects as the mimesis of the divine order - that is precisely delight. Nevertheless, Lyon merely talks about one aspect of delight — what she says is only the first participation of the rational soul. Actually, according to the argumentation in this part, it can be inferred that "delight" involves not only the intellect recognition of sensory objects as the mimesis of the divine order but also the harmonious cooperation and obedience of the other parts of soul and the body - this is exactly why the second participation is necessary, as is stated by Johansen, "our rationality is not exhibited simply in rational contemplation in disregard of the influence of the body, but in the pursuit of a composite life of soul and body. Caring for the self, as we saw, extends to caring for the entire tripartite soul, not just for the intellect." [7].

\section{CONCLUSION}

To conclude, my own version of hearing modality mainly talks about two significant aspects about the role of the rational soul in hearing, namely its general working pattern and its cooperation with the mortal parts.

In terms of its general working pattern, the rational soul resembles the cognitive way of the world soulfirstly, the harmonious proportionate parts are rooted within its inner structure, and this provides it with an internal template that allows it to recognize things it encounters by the principle of "like is known by like"; secondly, it would actively recognize things instead of passively waiting for their arrival; finally, its cognitive pattern resembles the Great Comparison, which means that the intellectual cognition is a relational grasp of things instead of the immediate cognition.

As for the interaction between the rational soul and the mortal parts, the rational soul should participate twice in hearing to consummate its duty, which is modally represented as two routes in this article: in route 1 , the sound particles further travel to the brain, and the rational soul situated in the brain also actively reaches for them, while route 2 continues extending to the liver and then causes pleasure or pain in the appetitive soul. The first participation exactly happens in route 1 , and during this procedure the rational would gain access to what the hearing object is and thus intellectually analyze the information carried by the sound, whether it is harmony, speech or rhythm, due to the congruence between the framework of the soul and the hearing objects. Furthermore, the second participation happens after the appetitive soul sends its feedback to the rational part. At this time, the rational soul would make a comparison between the former analysis and the current feedback.

Nevertheless, there are some restrictions for the opinions within this essay. First of all, this essay merely focuses on the texts of the Timaeus and fails to connect it with other dialogues of Plato or other philosophers. Additionally, since this essay mainly focuses on the performance of the rational soul in hearing, the role of the mortal parts of soul and somatic organs are not attached the same importance to that of the rational soul. Further investigation is suggested to go deeper into the rational soul in hearing.

\section{REFERENCES}

[1] Plato. The Timaeus. Translated by Donald J. Zeyl. Cambridge: Hackett Publishing Company.

[2] T. K. Johansen. "Perception and Cosmology." Plato's Natural Philosophy--A study of the TimaeusCritias, Cambridge University Press, 2008, pp. 160177.

[3] Barker, Andrew. "Timaeus on music and the liver: In Reason and Necessity." Essays on Plato's. Timaeus, The Classical Press of Wales, 2000, pp.85-101.

[4] Lyon, Elizabeth Lucia. "Ethical Aspects of Listening in Plato's Timaeus." Greek and. Roman Musical Studies, vol.4, 2016, pp.253-272.

[5] The Phaedo. Oxford: Clarendon press, 1911.

[6] Corcilius, Klaus. "Ideal Intellectual Cognition in Tim.37a2-c5." 2017.

[7] T. K. Johansen. "Body, soul, and tripartition." Plato's Natural Philosophy--A study of the TimaeusCritias, Cambridge University Press, 2008, pp. 117137.

[8] Cornford. Plato's Cosmology--The Timaeus of Plato, Cambridge: Hackett Publishing. Company, 1997, pp. $275-320$.

[9] Wiskus, Jessica. "On Song, Logos and the Movement of the Soul: after Plato and. Aristotle." Revista Portuguesa de Filosofia, vol. 74, no.4, 2018, pp.917-934.

[10] Brisson, Luc. "Plato's theory of sense perceptions in the Timaeus: How it works and what it means." Proceedings of the Boston Area Colloquium of Ancient Philosophy, vol.13, 1997, pp. 147-176.

[11] Karfik, Filip. "What the mortal parts of the soul really are." A Journal for Ancient Philosophy and Science, vol.2, 2005, pp. 197-217. 